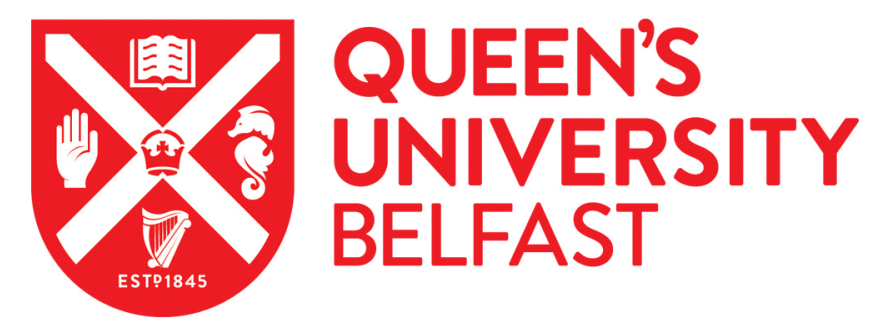

\title{
Familial idiopathic methemoglobinemia revisited: original cases reveal 2 novel mutations in NADH cytochrome b5 reductase
}

\author{
Percy, M. J., Gillespie, M. J. S., Savage, G., Hughes, A. E., McMullin, M. F., \& Lappin, T. R. J. (2002). Familial \\ idiopathic methemoglobinemia revisited: original cases reveal 2 novel mutations in NADH cytochrome b5 \\ reductase. Blood, 100(10), 3447-3449. https://doi.org/10.1182/blood-2002-05-1405
}

\section{Published in:}

Blood

Queen's University Belfast - Research Portal:

Link to publication record in Queen's University Belfast Research Portal

\section{General rights}

Copyright for the publications made accessible via the Queen's University Belfast Research Portal is retained by the author(s) and / or other copyright owners and it is a condition of accessing these publications that users recognise and abide by the legal requirements associated with these rights.

Take down policy

The Research Portal is Queen's institutional repository that provides access to Queen's research output. Every effort has been made to ensure that content in the Research Portal does not infringe any person's rights, or applicable UK laws. If you discover content in the Research Portal that you believe breaches copyright or violates any law, please contact openaccess@qub.ac.uk. 


\title{
Evidence for Association of Endothelial Nitric Oxide Synthase Gene in Subjects with Glaucoma and a History of Migraine
}

\author{
Joanne F. J. Logan, ${ }^{1}$ Usha Chakravarthy, ${ }^{2}$ Anne E. Hughes, ${ }^{2}$ Chris C. Patterson, ${ }^{3}$ \\ Jonathan A. Jackson, ${ }^{1,2,4}$ and Simon J. A. Rankin ${ }^{1}$
}

\begin{abstract}
Purpose. There is evidence to suggest that vasospasm and vascular dysregulation play a role in the etiology of glaucoma. This effect may be particularly relevant in patients with glaucoma who have a history of migraine or vasospastic tendencies. This study was conducted to investigate the role of genes with products that regulate blood flow to ocular tissues. The candidate genes were the two isoforms of nitric oxide synthase (NOS), NOS3 and -2A, and endothelin (ET)-1. The frequency of the T786C mutation in NOS3 was also examined.
\end{abstract}

Methods. DNA was obtained from 58 patients with primary open-angle glaucoma (POAG), 76 with normal tension glaucoma (NTG), and 38 control subjects. Polymerase chain reactions (PCR) were used to compare the frequency of the alleles between the subjects with glaucoma and the control subjects and the subjects with glaucoma with vasospasm or migraine. The PCR product was sequenced to identify the frequency of the T786C mutation.

Results. The distribution of the NOS3 repeat alleles in subjects with glaucoma and control subjects just failed to reach statistical significance $(P=0.06)$. The distribution in subjects with NTG or POAG did not differ significantly. A significant difference was found $(P<0.001)$ in the distribution of allele frequencies of the NOS3 marker in subjects who had glaucoma with migraine versus control subjects. There were no differences in the distribution of the NOS2A or ET-1 markers between the subjects with glaucoma and the control subjects.

Conclusions. This study provides evidence of an association between the NOS3 gene and subjects with glaucoma who have a history of migraine. Unlike in other studies, no evidence was found of an association between ET-1 and glaucoma. (Invest Ophthalmol Vis Sci. 2005;46:3221-3226) DOI:10.1167/iovs.050368

From the ${ }^{1}$ Department of Ophthalmology, The Royal Group of Hospitals, Belfast, United Kingdom; the ${ }^{2}$ Centre for Vision Science and the ${ }^{3}$ Department of Epidemiology and Public Health, Queen's University, Belfast, United Kingdom; and the ${ }^{4}$ Faculty of Biomedical Sciences, University of Ulster, Coleraine, United Kingdom.

Supported by grants from the Research and Development Office of Health and Personal Social Services (HPSS) in Northern Ireland and the British Council for the Prevention of Blindness.

Submitted for publication March 23, 2005; accepted April 11, 2005.

Disclosure: J.F.J. Logan, None; U. Chakravarthy, None; A.E. Hughes, None; C.C. Patterson, None; J.A. Jackson, None; S.J.A. Rankin, None

The publication costs of this article were defrayed in part by page charge payment. This article must therefore be marked "advertisement" in accordance with 18 U.S.C. $\$ 1734$ solely to indicate this fact.

Corresponding author: Joanne F. J. Logan, Department of Ophthalmology, The Royal Group of Hospitals, Belfast, United Kingdom; joanne.logan1@btopenworld.com.
$\mathrm{T}$ here is accumulating evidence that vasospasm and vascular dysregulation predispose to the development of glaucoma. A compromised blood supply to the optic nerve head in glaucoma has been implicated in the pathogenesis of optic nerve damage. ${ }^{1-5}$ The prevalence of vasospastic symptoms such as a history of migraine and cold extremities is higher in those with normal tension glaucoma (NTG) than in those with primary open-angle glaucoma (POAG) ${ }^{3,4,6,7}$ Genes with products that are involved in the regulation of blood flow to ocular tissues may be considered plausible candidates for studies on genetic variability as a contributory factor in the development of glaucoma.

Nitric oxide (NO) maintains the basal vasodilator tone. It is synthesized in the vascular endothelium through the action of endothelial nitric oxide synthase (NOS) on the substrate Larginine (eNOS, or NOS3). ${ }^{8}$ NOS isoforms are found in ocular tissues, and the role of NO in regulating the circulation in this organ is undisputed. Systemic inhibition of NOS reduces the pulsatile choroidal blood flow in young, healthy volunteers. Substantial evidence implicates abnormalities in NOS expression and regulation in disorders that affect the microcirculation of the eye and other organs. First, abnormalities in vasodilatory responses have been shown in the microcirculation of the forearm in patients with NTG. ${ }^{10}$ Second, $20 \%$ of patients with familial POAG have a polymorphism in the 5 ' flanking region of the eNOS gene, ${ }^{11}$ suggesting that this polymorphism may alter eNOS expression and thus NO synthesis. Third, NOS mutations have been implicated in vasospastic disease elsewhere in the body, and a study of NOS3 discovered a mutant allele (T786C) in $28 \%$ of subjects with coronary spasm, with only $7 \%$ of control subjects exhibiting this mutation. ${ }^{12}$ In this study, carriage of the mutant allele conferred the highest risk for coronary spasm, followed by cigarette smoking, leading the investigators to conclude that the presence of the mutant allele reduced NO synthesis and that carriership predisposed to coronary spasm.

Endothelin (ET)-1 is a potent vasoactive peptide that induces strong vasoconstriction in the vascular bed ${ }^{13}$ and has been implicated in systemic vasospastic disorders. ${ }^{14,15}$ Increased plasma levels of ET- ${ }^{16}$ and abnormal postural responses to ET- $1^{17}$ have been documented in patients with NTG, suggesting a dysfunctional endothelium in such individuals. Investigations of ET-1 pathophysiology with respect to the eye suggest that abnormalities exist in experimental models and in subgroups of patients with glaucoma. ${ }^{16-20}$

Based on the foregoing, we postulated that polymorphic variability in genes involved in the regulation of vasoactive agents could alter susceptibility to glaucoma. We selected the two isoforms of NOS that are expressed in the vasculatureNOS3 and NOS2A - and the vasoconstrictor ET-1 as candidate genes for the present study. Our purpose was to examine the association between the frequency distribution of alleles of genetic markers for NOS3, NOS2A, and ET-1 in patients with NTG or POAG and in control subjects without glaucoma. We also chose to examine the frequency of the T786C mutation in 
TABLE 1. The PCR Primers

Forward Primer

$\operatorname{NOS} 3^{21}$

$\operatorname{NOS} 2 \mathrm{~A}^{22}$

ET- 13

T-786C mutation
5' TGAGGAGAGACTCAGAATTGGA 3'

5' ACCCCTGGAAGCCTACAACTGCAT 3'

5' GATGGACAGAGAAGGCAGGTG 3'

5' TGA AGT GCC TGG AGA GTG CTG G 3'
Reverse Primer

5' GCTGTGTGGGGTTTCAGGCT 3'

5' GCCACTGCACCCTAGCCTGTCTCA 3'

5' TGAATTTGCAAGACGTGTGC 3'

5' AGC AGA GAG ACT AGG GCT GAG G 3' the disease population relative to control subjects. The subjects with glaucoma with a history of migraine or vasospastic symptoms were of particular interest and were analyzed as subgroups.

\section{Methods}

\section{Subjects}

Cases were subjects with either POAG or NTG and were recruited from a specialist glaucoma clinic at the Royal Group of Hospitals (Belfast, UK). The study was conducted in full accord with the tenets of Declaration of Helsinki regarding research involving human volunteers, and approval for all research procedures was obtained from the Research Ethics Committee, Queen's University Belfast, before commencing subject recruitment. Subjects with POAG fulfilled the following criteria: (1) glaucomatous optic nerve head damage in at least one eye, as diagnosed by a glaucoma specialist; (2) a reproducible glaucomatous visual field defect with the Humphrey 24-2 full-threshold strategy (Carl Zeiss Meditec, Oberkochen, Germany); (3) a presenting intraocular pressure (IOP) of $>21 \mathrm{~mm} \mathrm{Hg}$ in at least one eye on repeated testing by Goldmann applanation tonometry; and (4) open anterior chamber angles bilaterally.

Criteria for selection of subjects with NTG were identical, except median IOP was required to be $<21 \mathrm{~mm} \mathrm{Hg}$ on a diurnal curve of no fewer than five readings, in both eyes. One spike of $24 \mathrm{~mm} \mathrm{Hg}$ was accepted.

Exclusion criteria were a history of diabetes or other ocular diseases that may damage the optic nerve, presence of age-related macular degeneration or any other retinal disease, and a history of intraocular surgery apart from cataract extraction and trabeculectomy.

Control subjects were recruited among the general population and spouses of patients with glaucoma and through referrals from optometrists. Participants were accepted as control subjects when IOP was $<21 \mathrm{~mm} \mathrm{Hg}$ bilaterally, with open anterior chamber angles, bilateral healthy optic nerve heads and healthy fundi, and a visual field test with the Humphrey 24-2 full-threshold strategy showing no evidence of glaucomatous defects. Exclusion criteria were intraocular surgery (apart from cataract surgery), a positive family history of glaucoma, and the presence of diabetes.

All subjects had a spherical refractive error of $<7 \mathrm{D}$, astigmatism of $<2 \mathrm{D}$, and visual acuity of better than $0.3 \log$ MAR (logarithm of the minimum angle of resolution) in at least one eye. The peak IOP of each subject was obtained from hospital case records. A detailed medical history of each subject was obtained, including a history of migraine headaches and the subjective temperature of their extremities. Subjects who responded that their hands or feet go white and numb in the cold were recorded as having peripheral vasospastic symptoms. Subjects were asked if they had a first-degree relative with glaucoma.

\section{DNA Extraction}

Ten milliliters of blood was obtained from each of the subjects participating in the study. A DNA isolation kit (Puregene; Gentra Systems, Minneapolis, MN) was used to isolate DNA from whole blood by using standard methodology. A PCR System (GeneAmp; Applied Biosystems, Inc. $[\mathrm{ABI}]$, Foster City, $\mathrm{CA})$ was used to perform the PCR reactions. After amplification, the PCR product was size fractionated by electrophoresis on a genetic analyzer (Prism 3100; ABI). To identify the frequency of the T786C mutation in the NOS3 gene, the PCR products were sequenced with the genetic analyser. The primers for each of the candidate genes and the T786C mutation in the NOS3 gene are displayed in Table 1.

\section{Statistical Methods}

One-way analysis of variance and $\chi^{2}$ tests were used to test for differences in demographic and clinical parameters between cases and control subjects, with a significance level of 0.05 . Allele frequencies were compared between subjects with glaucoma and control subjects, with the $\chi^{2}$ test for $2 \times n$ tables, where $n$ is the number of alleles. Rare alleles were pooled so that all expected cell values were greater than 2. $P<0.05$ was considered significant. When this initial comparison of groups yielded a significant result, each allele was considered on its own, with the other alleles pooled to give a series of $2 \times 2$ tables. A Bonferroni correction was applied to take into account the number of alleles $(m)$ considered. The probabilities for such tests are reported in both uncorrected $(P)$ and corrected $\left(P_{\mathrm{c}}=m P\right)$ form. The odds ratio and $95 \%$ confidence interval were calculated to examine the association of the alleles with disease status. We investigated the combinations of the NOS3 promoter polymorphism and the microsatellite marker (haplotypes) in the glaucoma patients with migraine versus control subjects, by using the PHASE program (ver. 2). ${ }^{24}$

\section{Sample Size}

The planned study size of 130 subjects with glaucoma and 40 control subjects was sufficient to detect a $20 \%$ difference in the allele frequencies between subjects with glaucoma and control subjects for an allele with a frequency of $10 \%$ in control subjects, with $80 \%$ power at the $5 \%$ significance level (and incorporating the Bonferroni correction for the multiple testing of an anticipated 10 alleles).

\section{Results}

The distribution and demographic details of the subjects with POAG or NTG and the unaffected control subjects are displayed in Table 2 . Fifty-eight patients with POAG (38 men and 20 women; mean age, $66.59 \pm 8.88$ years) and 76 patients with NTG (25 men and 51 women; mean age, $66.59 \pm 9.49$ years) were recruited. Thirty-eight control subjects (18 men and 20 women; mean age, $61.08 \pm 10.68$ years) were recruited. All subjects were white.

Approximately one third of all those with glaucoma reported a positive family history, with a similar proportion in both the NTG and POAG groups (30\% and 43\%, respectively). A positive history of migraine and presence of cold extremities were significantly higher in subjects with glaucoma than in control subjects (Table 2).

\section{NOS3}

The frequencies of NOS3 marker alleles in patients with glaucoma and control subjects are shown in Table 3. After rare alleles were pooled, the distribution of alleles just failed to reach significance $(P=0.06)$.

On examination of the distribution of allele frequencies of the NOS3 marker in subjects who have glaucoma with mi- 
TABLE 2. Subject Demographics

\begin{tabular}{|c|c|c|c|c|}
\hline & $\begin{array}{c}\text { NTG } \\
(n=76)\end{array}$ & $\begin{array}{c}\text { POAG } \\
(n=58)\end{array}$ & $\begin{array}{l}\text { Control } \\
(n=38)\end{array}$ & $\boldsymbol{P}$ \\
\hline $\begin{array}{l}\text { Highest IOP }(\mathrm{mm} \mathrm{Hg}) \\
\text { Mean } \pm \mathrm{SD}(\text { range })\end{array}$ & $\begin{array}{c}16.0 \pm 2.7 \\
(10-22)\end{array}$ & $\begin{array}{l}29.6 \pm 4.8 \\
(23-50)\end{array}$ & $\begin{array}{l}14.8 \pm 3.2 \\
(6-20)\end{array}$ & $<0.001 \ddagger$ \\
\hline Mean deviation $(\mathrm{dB})^{*}$ & $-10.6 \pm 6.3$ & $-10.3 \pm 5.7$ & $-1.1 \pm 1.6$ & $<0.001 \neq$ \\
\hline Mean \pm SD (range) & $(-28.2$ to -0.7$)$ & $(-27.0$ to -2.6$)$ & $(-5.9$ to 1.8$)$ & \\
\hline CPSD (dB) $\dagger$ & $9.6 \pm 4.0$ & $8.9 \pm 3.4$ & $1.2 \pm 0.7$ & $<0.001 \ddagger$ \\
\hline Mean \pm SD (range) & (0 to 15.4$)$ & (2.9 to 15.5$)$ & $(0$ to 3.1$)$ & \\
\hline History of migraine, $n(\%)$ & $18(23.7)$ & $7(12.1)$ & $3(7.9)$ & $=0.05^{\S}$ \\
\hline History of cold extremities, $n(\%)$ & $21(27.6)$ & $6(10.3)$ & $3(7.9)$ & $=0.006^{\S}$ \\
\hline
\end{tabular}

* Mean deviation is the Humphrey visual field global index.

$\dagger$ CPSD is the corrected pattern standard deviation visual field global index.

‡ ANOVA.

§Chi-square.

graine versus control subjects, a highly significant difference was found (Table 4).

When subjects with glaucoma with only peripheral vasospastic symptoms were compared against the control subjects, there were no significant differences between the groups in the distribution of the allele frequencies for the NOS3 marker.

The frequency of the T786C mutation of the NOS3 gene in our disease population is shown in Table 5. The frequencies of the genotypes did not depart significantly from those predicted by the Hardy-Weinberg equilibrium. There were no significant differences in the incidence of the mutant allele between the subjects with glaucoma and the control subjects (odds ratio, 0.96; $95 \%$ CI: $0.54-1.72$ ) or the subjects with glaucoma with migraine and the control subjects (odds ratio, 0.86; 95\% CI, $0.38-1.97)$.

Haplotype analysis, investigating the combination of the NOS3 promoter polymorphism and the microsatellite marker between the subjects with glaucoma with migraine and the control subjects, showed a statistically significant difference $(P=0.02)$. Data not shown.

\section{NOS2A}

There were no significant differences between subjects with glaucoma and control subjects in the distribution of the allele frequencies for the NOS2A marker (Table 6). When subjects with glaucoma with peripheral vasospastic symptoms and migraine were compared against control subjects, there were no significant differences in the distribution of the allele frequencies for the NOS2A marker.

\section{Endothelin-1}

Comparison of all subjects with glaucoma and control subjects showed no significant differences in the distribution of the

TABLE 3. Distribution of the NOS3 Repeat Alleles in Subjects with Glaucoma and Controls

\begin{tabular}{|c|c|c|c|c|}
\hline \multirow[b]{2}{*}{$\begin{array}{c}\text { NOS3 Alleles } \\
\text { (bp) }\end{array}$} & \multicolumn{2}{|c|}{ Glaucomas $(n=131)$} & \multicolumn{2}{|c|}{ Control $(n=37)$} \\
\hline & $\begin{array}{c}\text { Alleles } \\
(n)\end{array}$ & Frequency & $\begin{array}{l}\text { Alleles } \\
(n)\end{array}$ & Frequency \\
\hline $141^{*}$ & 1 & 0.004 & 0 & 0.000 \\
\hline $143^{*}$ & 1 & 0.004 & 4 & 0.054 \\
\hline $145^{*}$ & 3 & 0.011 & 0 & 0.000 \\
\hline 147 & 10 & 0.038 & 4 & 0.054 \\
\hline $149^{*}$ & 2 & 0.008 & 1 & 0.014 \\
\hline $151^{*}$ & 6 & 0.023 & 1 & 0.014 \\
\hline $153^{*}$ & 3 & 0.011 & 1 & 0.014 \\
\hline $155^{*}$ & 4 & 0.015 & 0 & 0.000 \\
\hline 157 & 16 & 0.061 & 0 & 0.000 \\
\hline 159 & 15 & 0.057 & 1 & 0.014 \\
\hline 161 & 22 & 0.084 & 6 & 0.081 \\
\hline 163 & 18 & 0.069 & 9 & 0.122 \\
\hline 165 & 31 & 0.118 & 3 & 0.041 \\
\hline 167 & 30 & 0.115 & 7 & 0.095 \\
\hline 169 & 38 & 0.145 & 8 & 0.108 \\
\hline 171 & 19 & 0.073 & 9 & 0.122 \\
\hline 173 & 21 & 0.080 & 9 & 0.122 \\
\hline 175 & 11 & 0.042 & 6 & 0.081 \\
\hline $177^{*}$ & 6 & 0.023 & 1 & 0.014 \\
\hline $179^{*}$ & 3 & 0.011 & 0 & 0.000 \\
\hline $181^{*}$ & 2 & 0.008 & 3 & 0.041 \\
\hline $191^{*}$ & 0 & 0.000 & 1 & 0.014 \\
\hline Total & 262 & 1.000 & 74 & 1.000 \\
\hline
\end{tabular}

Statistical significance $\chi^{2}=18.8, d f=11 ; P=0.06$. The distribution in NTG and POAG subjects did not differ significantly.

* indicates the alleles that were pooled for the analysis. 
TABLE 4. Distribution of the NOS3 Repeat Alleles in the Subjects with Glaucoma and Migraine and the Controls

\begin{tabular}{|c|c|c|c|c|}
\hline \multirow[b]{2}{*}{ NOS3 Alleles (bp) } & \multicolumn{2}{|c|}{$\begin{array}{c}\text { Glaucoma with Migraine } \\
\qquad(n=25)\end{array}$} & \multicolumn{2}{|c|}{$\begin{array}{l}\text { Control } \\
(n=37)\end{array}$} \\
\hline & Alleles $(n)$ & Frequency & Alleles $(n)$ & Frequency \\
\hline 147 & 2 & 0.040 & 4 & 0.054 \\
\hline 157 & 5 & 0.100 & 0 & 0.000 \\
\hline 159 & 4 & 0.080 & 1 & 0.014 \\
\hline 161 & 2 & 0.040 & 6 & 0.081 \\
\hline 163 & 2 & 0.040 & 9 & 0.122 \\
\hline 165 & 3 & 0.060 & 3 & 0.041 \\
\hline $167^{*}$ & 16 & 0.320 & 7 & 0.095 \\
\hline 169 & 8 & 0.160 & 8 & 0.108 \\
\hline 171 & 3 & 0.060 & 9 & 0.122 \\
\hline 173 & 0 & 0.000 & 9 & 0.122 \\
\hline 175 & 3 & 0.060 & 6 & 0.081 \\
\hline Pooled alleles $\dagger$ & 2 & 0.040 & 12 & 0.160 \\
\hline Total & 50 & 1.000 & 74 & 1.000 \\
\hline
\end{tabular}

Statistical significance $\chi^{2}=34.2, d f=11 ; P<0.001$.

* The 167 allele has a significantly different frequency between cases and controls after correcting for multiple comparisons $\left(P=0.002, P_{\mathrm{c}}=0.02\right)$.

† Alleles $143,145,149,151,153,155,177,179,181$, and $191 \mathrm{bp}$.

allele frequencies for the ET-1 marker (Table 6). When subjects with glaucoma were subcategorized on the basis of a positive history of peripheral vasospastic symptoms or migraine, the distribution of the allele frequencies for the ET-1 marker was not significantly different from the control population.

\section{Discussion}

The vascular endothelium plays an important role in the control of vascular functions. It regulates the perfusion of blood by releasing agents that are responsible for vasodilation and vasoconstriction and by modifying their release in response to local metabolic needs. The candidate genes examined in this study-NOS3, NOS2A, and ET-1-were selected because their products control ocular blood flow and also because they have been implicated in the pathogenesis of ocular disorders that occur as a consequence of vascular dysregulation.

The following observations support the hypothesis of a dysfunction of the endothelium-mediated vasodilatory response in glaucoma. The pulsatile element of choroidal blood flow has been shown to reduce after systemic infusion of L-NMMA ( $N^{\mathrm{G}}$-monomethyl-L-arginine; a competitive inhibitor of NO synthase) in healthy volunteers, ${ }^{9}$ leading the investigators to speculate that systemic endothelial dysfunction, such as that found in diabetes or hypertension, may affect ocular hemodynamics. It has been shown that patients with glaucoma have a significantly lower increase in forearm blood flow than do control subjects after infusion of acetylcholine (an endothelialdependent vasodilator). ${ }^{10}$

On examination of polymorphic variability in the genes encoding constitutive NOS (NOS3 or eNOS), a difference that was of borderline significance was observed in the distribution of its alleles between subjects with glaucoma and control subjects. Our findings are therefore partly in accord with an association study that found $20 \%$ of those with familial POAG had a polymorphism in the $5^{\prime}$ flanking region of the NOS3 gene. ${ }^{11}$ This study included subjects with POAG only (IOP greater than $21 \mathrm{~mm} \mathrm{Hg}$ ). Because we investigated two markers in the same gene, we were able to undertake haplotype analysis. The results of this analysis were in accord with the findings. The differential distribution of NOS3 alleles may reflect in a change in NOS3 expression that alters the NO concentration.

Subjects with migraine are believed to have a dysfunctional vasodilatory response that may be linked to polymorphisms in the NOS3 gene. Consistent with this observation, the present study found that the distribution of NOS3 alleles was significantly different in subjects who had glaucoma with migraine when compared with control subjects without glaucoma. The Collaborative Normal-Tension Glaucoma Study found that patients with migraine, particularly women, had a more rapid course of glaucoma progression than those without a history of

TABLE 5. Frequencies of the Genotypes and Alleles of the NOS3 Gene

\begin{tabular}{|c|c|c|c|c|c|}
\hline & $\begin{array}{l}\text { Glaucoma, } n(\%) \\
\quad(n=117)\end{array}$ & $\begin{array}{c}\text { Glaucoma and } \\
\text { Migraine, } n(\%) \\
\quad(n=24)\end{array}$ & $\begin{array}{c}\text { Control, } \\
n(\%) \\
(n=36)\end{array}$ & $\begin{array}{l}\text { Glaucoma Odds } \\
\text { Ratio (95\% CI) }\end{array}$ & $\begin{array}{l}\text { Glaucoma and } \\
\text { Migraine Odds } \\
\text { Ratio (95\% CI) }\end{array}$ \\
\hline \multicolumn{6}{|l|}{ Genotype } \\
\hline Normal homozygote & $45(38.5)$ & $10(41.7)$ & $13(36.1)$ & & \\
\hline Heterozygote & $55(47.0)$ & $11(45.8)$ & $18(50.0)$ & & \\
\hline Abnormal homozygote & $17(14.5)$ & $3(12.5)$ & $5(13.9)$ & & \\
\hline \multicolumn{6}{|l|}{ Allele } \\
\hline Normal & $145(62.0)$ & $31(64.6)$ & $44(61.1)$ & 1.00 & \\
\hline Abnormal & $89(38.0)$ & $17(35.4)$ & $28(38.9)$ & $0.96(0.54-1.72)$ & $0.86(0.38-1.97)$ \\
\hline
\end{tabular}

Statistical significance (glaucoma and controls): $\chi^{2}=0.10, d f=2, P=0.95$ (genotypes): $\chi^{2}=0.02, d f=1, P=0.90$ (alleles). Statistical significance (glaucoma with migraine and controls): $\chi^{2}=0.19$, $d f=2, P=0.91$; (genotypes): $\chi^{2}=0.15, d f=1, P=0.70$ (alleles). 
TABLE 6. Distribution of the NOS2A and ET-1 Repeat Alleles in Subjects with Glaucoma and Controls

\begin{tabular}{|c|c|c|c|c|c|c|c|c|c|}
\hline \multirow{2}{*}{$\begin{array}{l}\text { NOS2A } \\
\text { Alleles } \\
\text { (bp) }\end{array}$} & \multicolumn{2}{|c|}{$\begin{array}{l}\text { Glaucoma Subjects } \\
\qquad(n=131)\end{array}$} & \multicolumn{2}{|c|}{$\begin{array}{l}\text { Controls } \\
(n=38)\end{array}$} & \multirow{2}{*}{$\begin{array}{c}\text { ET-1 } \\
\text { Alleles } \\
\text { (bp) }\end{array}$} & \multicolumn{2}{|c|}{$\begin{array}{l}\text { Glaucoma Subjects } \\
\qquad(n=131)\end{array}$} & \multicolumn{2}{|c|}{$\begin{array}{l}\text { Control } \\
(n=36)\end{array}$} \\
\hline & $\begin{array}{l}\text { Alleles } \\
(n)\end{array}$ & Frequency & $\begin{array}{l}\text { Alleles } \\
\quad(n)\end{array}$ & Frequency & & $\begin{array}{l}\text { Alleles } \\
(n)\end{array}$ & Frequency & $\begin{array}{l}\text { Alleles } \\
(n)\end{array}$ & Frequency \\
\hline $176^{*}$ & 1 & 0.004 & 1 & 0.013 & $190^{*}$ & 4 & 0.015 & 0 & 0.000 \\
\hline 181 & 16 & 0.061 & 2 & 0.026 & 192 & 15 & 0.057 & 7 & 0.097 \\
\hline 186 & 31 & 0.118 & 7 & 0.092 & 194 & 96 & 0.366 & 24 & 0.333 \\
\hline 191 & 54 & 0.206 & 17 & 0.224 & 196 & 40 & 0.153 & 11 & 0.153 \\
\hline 196 & 89 & 0.340 & 27 & 0.355 & 198 & 40 & 0.153 & 10 & 0.139 \\
\hline 201 & 38 & 0.145 & 11 & 0.145 & 200 & 27 & 0.103 & 4 & 0.056 \\
\hline 206 & 21 & 0.080 & 8 & 0.105 & 202 & 6 & 0.023 & 5 & 0.069 \\
\hline $211^{*}$ & 6 & 0.023 & 2 & 0.026 & 204 & 18 & 0.069 & 6 & 0.083 \\
\hline $216^{*}$ & 5 & 0.019 & 1 & 0.013 & 206 & 9 & 0.034 & 2 & 0.028 \\
\hline \multirow[t]{2}{*}{$221^{*}$} & 1 & 0.004 & 0 & 0.000 & $208^{*}$ & 3 & 0.011 & 2 & 0.028 \\
\hline & & & & & $210^{*}$ & 4 & 0.015 & 1 & 0.014 \\
\hline Total & 262 & 1.000 & 76 & 1.000 & Total & 262 & 1.000 & 72 & 1.000 \\
\hline
\end{tabular}

NOS2a: $\chi^{2}=2.27, d f=6, P=0.89$; ET-1: $\chi^{2}=6.94, d f=8, P=0.54$; the distribution of the alleles in the NTG and POAG subjects did not differ significantly.

* Alleles that were pooled for the analysis.

migraine. ${ }^{25}$ However, a study in which the NOS3 gene was investigated in migraine etiology found no association or linkage. $^{26}$ Therefore, although migraine is a risk factor for glaucoma, it is likely that many other predisposing factors exist.

In the present study, unlike the Japanese coronary spasm study, there was no difference in the frequency of the abnormal allele in the T786C mutation of the NOS3 gene in our subjects with glaucoma. ${ }^{12}$

We specifically investigated the gene encoding NOS2A because it has been proposed that excessive NO released by astrocytes through increased expression of this gene damages the axons of the retinal ganglion cells. ${ }^{27}$ NOS2A is mainly expressed in response to injury, inflammation, and ischemia in vascular or nonvascular cells. In the study by Neufeld that used a rat model with elevated IOP, inhibition of NOS2A protected against axon loss. However, in the present study we did not find differences in the distribution of NOS2A in subjects with glaucoma and control subjects.

Despite the evidence suggesting that ET-1 plays a role in the pathogenesis of glaucoma, ${ }^{16,18,20,28}$ the present study found no evidence to support such an association, as the distribution of allele frequencies for an ET-1 gene marker did not differ between subjects with glaucoma and the control population. However, we only tested one marker, and our sample size was small, therefore the possibility of an effect cannot be discounted.

The major strength of the present study is the careful phenotyping of patients with glaucoma and clear definitions to separate cases from control subjects. To the best of our knowledge despite exhaustive Medline searching, no similar studies were identified. In summary, the present study has demonstrated differences in the distribution of NOS3 alleles in a glaucoma population compared with a control group. We believe that additional studies on separate populations are needed to confirm this association.

\section{Acknowledgments}

The authors thank David McGibbon for assistance with the laboratory work.

\section{References}

1. Drance SM, Sweeney VP, Morgan RW, et al. Studies of factors involved in the production of low tension glaucoma. Arch Ophthalmol. 1973;89:457-465.
2. Hayreh SS, Zimmerman MB, Podhajsky P, et al. Nocturnal arterial hypotension and its role in optic nerve head and ocular ischemic disorders. Am J Ophthalmol. 1994;117:603-624.

3. Phelps CD, Corbett JJ. Migraine and low tension glaucoma: a case control study. Invest Ophthalmol Vis Sci. 1985;26:1105-1108.

4. Gasser P, Flammer J. Blood cell velocity in the nailfold capillaries of patients with normal-tension and high-tension glaucoma. $\mathrm{Am} \mathrm{J}$ Ophthalmol. 1991;111:585-588.

5. Flammer J, Gasser P, Prunte CH, et al. The probable involvement of factors other than ocular pressure in the pathogenesis of glaucoma. In: Drance SM, Van Buskirk EM, Neufeld AH, eds. Pharmacology of Glaucoma. Baltimore: Williams \& Wilkins; 1992:273283.

6. Corbett JJ, Phelps CD, Eslinger P, et al. The neurologic evaluation of patients with low tension glaucoma. Invest Ophthalmol Vis Sci. 1985;26:1101-1104.

7. Drance SM, Douglas GR, Wijsman K, et al. Response of blood flow to warm and cold in normal and low-tension glaucoma patients. Am J Ophthalmol. 1988;105:35-39.

8. Marletta MA. Nitric oxide synthase structure and mechanism. J Biol Chem. 1993;268:12231-12234.

9. Schmetterer L, Krejcy K, Kastner J, et al. The effect of systemic nitric oxide-synthase inhibition on ocular fundus pulsations in man. Exp Eye Res. 1997;64:305-312.

10. Henry E, Newby DE, Webb DJ, et al. Peripheral endothelial dysfunction in normal pressure glaucoma. Invest Ophthalmol Vis Sci. 1999; 40:1710-1714.

11. Tunny TJ, Richardson KA, Clark CV. Association study of the $5^{\prime}$ flanking regions of endothelial-nitric oxide synthase and endothelin-1 genes in familial primary open-angle glaucoma. Clin Exp Pharmacol Physiol. 1998;25:26-29.

12. Nakayama M, Yasue $\mathrm{H}$, Yoshimura $\mathrm{M}$, et al. $\mathrm{T}^{786}-\mathrm{C}$ mutation in the 5 flanking region of the endothelial nitric oxide synthase gene is associated with coronary spasm. Circulation. 1999;99:28642870.

13. Yanagisawa M, Kurihara H, Kimura S, et al. A novel potent vasoconstrictor peptide produced by vascular endothelial cells. $\mathrm{Na}$ ture. 1988;332:411- 415 .

14. Lüscher TF. Endothelin: key to coronary vasospasm? Circulation. 1991;83:701-703.

15. Miyauchi $T$, Yanagisawa $M$, Tomizawa $T$, et al. Increased plasma concentrations of endothelin-1 and big endothelin-1 in acute myocardial infarction. Lancet. 1989;2(8653):53-54.

16. Sugiyama T, Moriya S, Oku H, et al. Association of endothelin-1 with normal tension glaucoma: clinical and fundamental studies. Surv Ophthalmol. 1995;39(suppl 1):S49-S56. 
17. Kaiser HJ, Flammer J, Wenk M, et al. Endothelin-1 plasma levels in normal-tension glaucoma: abnormal response to postural changes. Graefes Arch Clin Exp Opbthalmol. 1995;233:484-488.

18. Orgül S, Cioffi GA, Bacon DR, et al. An endothelin-1-induced model of chronic optic nerve ischemia in rhesus monkeys. J Glaucoma. 1996;5:135-138.

19. Shichiri M, Hirata Y, Ando K, et al. Postural change and volume expansion affect plasma endothelin levels. JAMA. 1990;263:661.

20. Tezel G, Kass MA, Kolker AE, et al. Plasma and aqueous humor endothelin levels in primary open-angle glaucoma. J Glaucoma. 1997;6:83-89.

21. Nadaud S, Bonnardeaux MD, Lathrop M, et al. Gene structure, polymorphism and mapping of the human endothelial nitric oxide synthase gene. Biochem Biophys Res Commun. 1994;198:10271033.

22. Xu W, Liu L, Emson PC, et al. Evolution of a homopurinehomopyrimidine pentanucleotide repeat sequence upstream of the human inducible nitric oxide synthase gene. Gene. 1997; 204:165-170.
23. Pages J-C, Drieu $\mathrm{C}$, Blanche $\mathrm{H}$, et al. A short tandem repeat polymorphism at the endothelin-1 (EDN1) locus. Hum Mol Genet. 1993;2:90.

24. Stephens M, Donnelly P. A comparison of Bayesian methods for haplotype reconstruction from population genotype data. Am J Hum Genet. 2003;73:1162-1169.

25. Drance SM, Anderson DR, Schulzer M. Risk factors for progression of visual field abnormalities in normal-tension glaucoma. For The Collaborative Normal-tension Glaucoma Study Group. Am J Ophthalmol. 2001;131:699-708.

26. Griffiths LR, Nyholt DR, Curtain RP, et al. Migraine association and linkage studies of an endothelial nitric oxide synthase (NOS3) gene polymorphism. Neurology. 1997;49:614-617.

27. Neufeld AH, Sawada A, Becker B. Inhibition of nitric-oxide synthase 2 by aminoguanidine provides neuroprotection of retinal ganglion cells in a rat model of chronic glaucoma. Proc Natl Acad Sci USA. 1999;96:9944-9948.

28. O'Brien C, Kelly PA, Ritchie IM. Effect of chronic inhibition of nitric oxide synthase on ocular blood flow and glucose metabolism in the rat. Br J Ophthalmol. 1997;81:68-71. 